Bangladesh Journal of Neuroscience 2014; Vol. 30 (1) : 57-61

\title{
Cauda Equina Syndrome due to Multiple Myeloma: A Case Report
}

\author{
MD. RASHEDUL ISLAM ${ }^{1}$, TANBIN RAHMAN ${ }^{2}$, RUMANAHABIB $^{3}$, AMINUR RAHMAN $^{4}$ \\ NIRMALENDU BIKASH BHOWMIC ${ }^{5}$, MD. AMIRUL HAQUE ${ }^{5}$
}

\begin{abstract}
:
Cauda equina compression following vertebral compression fractures or vertebral plasmacytomas is relatively uncommon presentation of multiple myeloma. Here we describe a case of cauda equina syndrome due to multiple myeloma in an elderly Bangladeshi male who presented with difficulty in walking, urinary complaints \& unexplained weight loss. CT guided FNAC from lesion of spine, bone marrow study, skeletal survey, MRI of spine \& immune electrophoresis confirmed the diagnosis of multiple myeloma. We treated the patient with radiotherapy, dexamethasone, antimyeloma therapy, physiotherapy \& bisphosphonates in collaboration with hematologists \& neurosurgeons. He showed significant improvement both clinically \& biochemically in the follow up.
\end{abstract}

\section{Introduction:}

Multiple myeloma (MM) is a clonal B-cell disorder characterized by proliferation and accumulation of B-lymphocytes and plasma cells in the bone marrow and, more rarely, at extramedullary sites. Bone disease occurs in approximately $80 \%$ of patients with newly diagnosed $\mathrm{MM}$, and in $70 \%$ of the cases bone pain is the first symptom to be reported at disease onset ${ }^{1}$ Pathological fractures, osteolyses, osteoporosis or, in general, skeletal-related events (SRE), that include also the need for radiotherapy or surgery to the bone, can severely impair patients quality of life and reduce survival ${ }^{2}$. Spine is the bone site that is most frequently affected by MM related lesions ${ }^{3}$.

Spinal cord compression (SCC) occurs in up to $20 \%$ of patients with $\mathrm{MM}$ at various disease stages 4 . The pathogenetic mechanisms are induced by displacement and compression of the spinal cord, and this can be caused by either epidural invasion by neoplastic tissue arising from a vertebral mass, or by osseous fragments protruding from a fractured vertebral body. Pain is the first and more common presenting symptom ${ }^{5,6}$. It is generally a mechanical pain caused by periosteal infiltration of the vertebrae, it becomes more intense in case of cough or labor, and it is further exacerbated when exerting pressure on the spinous processes. Radicular pain can also be present ${ }^{5,6}$. This can be caused by nerve-root compression and it is perceived according to the dermatomal distribution of the nerve root. Motor dysfunction is the second more frequent symptom of SCC. Patients complain about weakness of lower limbs, in particular when walking or going up the stairs. Sensory symptoms such as paresthesias, tingling, or numbness can occur simultaneously or after motor dysfunction; they usually precede autonomic-sphinteric symptoms that are usually represented by bladder dysfunction. ${ }^{5,6}$ Prompt recognition of these symptoms and subsequent intervention is mandatory as the picture invariably proceeds to paralysis that is frequently irreversible ${ }^{7}$.

MRI is the most sensitive and specific imaging technique to evaluate spinal lesions, as it allows morphological detection of vertebral compression fractures together with spatial evaluation of neural damage or paraspinal masses. The most interesting feature, however, is the possibility to evaluate the characteristics of bone marrow infiltration by the disease. MM related vertebral focal lesions present with a diffusely reduced signal in T1-weighted images and enhanced in T2-weighted images; bone marrow infiltration can thus be defined as "focal" when a clear number of lesions can be identified in the

1. Registrar, Department of Neurology, BIRDEM General Hospital, Dhaka.

2. MD (Hematology) Student, Dhaka Medical College, Dhaka.

3. Assistant Professor, Department of Neurology, BIRDEM General Hospital, Dhaka

4. Consultant, Department of Neurology, BIRDEM General Hospital, Dhaka.

5. Professor, Department of Neurology, BIRDEM General Hospital, Dhaka. 
context of a normal background; "diffuse" when all the bone marrow shows an altered signal, and "mixed" when both focal lesions and diffuse alteration are present ${ }^{8,9}$.

Regarding therapeutic approaches, decompressive laminectomy was frequently performed in the past but its use is now abandoned due to the residual instability of the vertebral column, to the possible delay in the beginning of antimyeloma therapy after surgery and, above all, to the sensitivity of neoplastic cells to steroids and radiotherapy, that now represent the mainstay of the treatment of SCC ${ }^{6}$. High-dose steroids, such as Dexamethasone at doses of 40 $60 \mathrm{mg} /$ day for $4-6$ days must be soon initiated upon recognition of SCC, aiming at obtaining both a plasmacytolitic and an antioedema effect. Radiotherapy must be also administered early ${ }^{10}$.

\section{Case report:}

A 65-year-old man presented to the Neurology department, BIREM for evaluation of two months of gradual onset of lower extremity weakness resulting in falls. He also reported a two day history of bladder retention. A systemic review of the patient was notable for dull but intense chronic back pain. He was no longer ambulatory, had left lower limb numbness and tingling, and had experienced an unintentional $10 \mathrm{~kg}$ of weight loss over the last six months. A systemic review of our patient was otherwise unremarkable.

On physical examination of our patient revealed anaemia, restricated spinal mobility \& tenderness on lower spine. He had wasting, hypotonia, diminished muscle power ( $2 / 5$ bilaterally), areflexia and absent plantar response in lower limbs. All modalities of sensation were diminished at L4/L5/ S1 dermatomal distribution on left side along with saddle anaestheisa \& reduced anal spincter tone. SLR was restricted on left side. Other findings on physical examination were unremarkable.

His hemoglobin of $8.1 \mathrm{~g} / \mathrm{dl}, 4,800 / \mathrm{cu} \mathrm{mm}$, Platelet$1,70,000 / \mathrm{cmm}$, ESR $120 \mathrm{~mm}$ in $1^{\text {st }}$ hour, PBF: Nonspecific morphology. Results for corrected serum calcium and coagulation studies were normal. His total protein level was $62 \mathrm{~g} / \mathrm{l}$ and his albumin level was $25 \mathrm{~g} / \mathrm{l}$. His alkaline phosphatase was $395 \mathrm{iu} / \mathrm{L}$.
Radiographic studies on admission included a normal chest radiograph and ECG. Magnetic resonance imaging (MRI) of his lumbar spine showed collapse with altered signal intensity in $L 5$ \& focal altered signal intensity in L1-L4, S1 vertebrae. Central \& paracentral disc bulge causing thecal sac indentation \& bilteral lateral recess narrowing at L5/ S1 level. Common tumor markers (CEA, CA 19-9, and PSA) were found to be normal. Serum protein electrophoresis demonstrated hypoproteinemia with hypoalbuminemia and borderline low gamma globulins. Urine protein electrophoresis didn't show Bence jones protein. Immuno electrophoresis revealed monoclonal light chains. X-ray lumbosacral spine revealed collapse $L 5$ vertebrae (Fig.-1). $X$ ray skull \& pelvis showed multiple lytic lesions (Fig.-2).

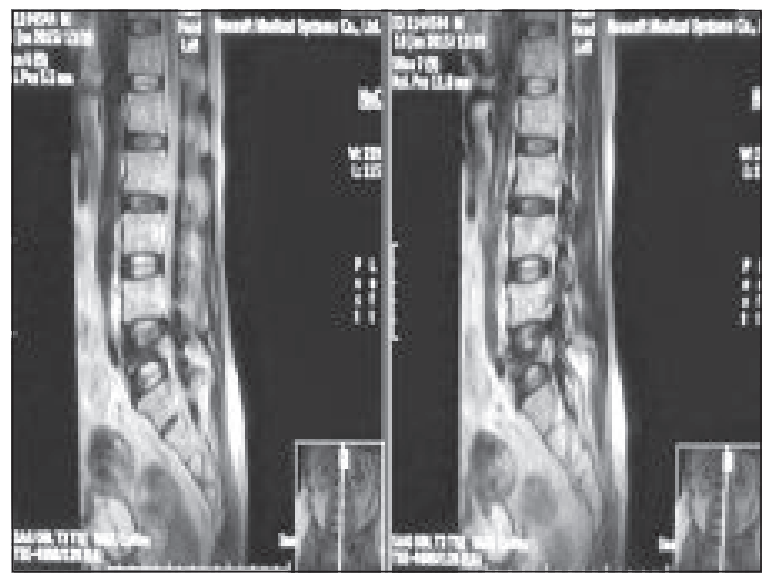

Fig.-1: X-ray of lumbosacral spine showing collapse lumbar vertebrae.

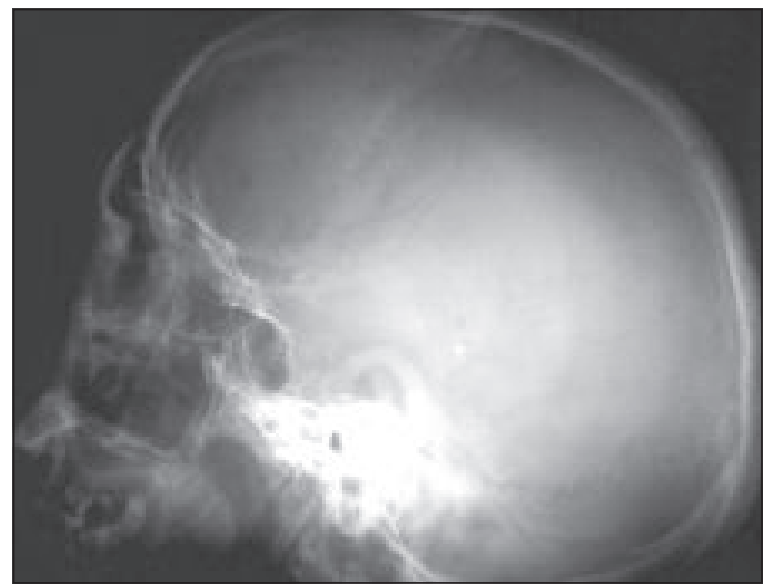

Fig.-2: X-ray of skull showing lytic lesions. 
Tissue from lumbar vertebral body L5 showed adequate cellular material containing numerous mononuclear cells having eccentric nuclei with abundant cytoplasm. Some of those cells had multiple nucleu. Bone marrow examination revealed grossly increased plasma cells almost completely replacing normal haemopoeitic cells replacing more than $80 \%$ of existing marrow cells. The cells are distributed in sheets \& clusters \& include some immature forms (Fig.-3).

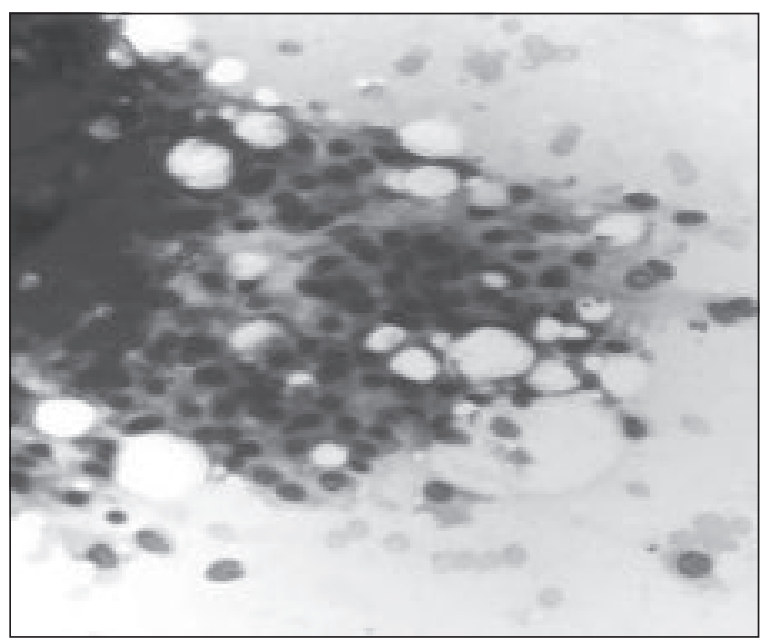

Fig.-3: Bone marrow examinations showing plasma cell.

\section{Discussion:}

This case presented a challenge in that our patient's initial presentation had a preponderance of lower extremity symptom. Thus, his pretest probability was highest for conditions affecting the lumbar spine, such as cauda equine syndrome from disc herniation or metastatic disease. The initial MRI of his lumbar spine in fact confirmed disc herniation with protrusion.

Our patient's history brings into consideration tuberculosis, particularly as an infection of the vertebral body (Pott's disease, tuberculous spondylitis, or tuberculoma), which most commonly manifests in adults ${ }^{11,12}$. The absence of tuberculosis in other locations does not exclude the diagnosis. Tuberculomas can have associated collapsed vertebrae and present with numbness, paraplegia and bladder disturbances similar to this presentation.
Other granulomatous diseases, such as sarcoidosis, were also considered as neurosarcoid lesions can resemble a tumor. Spinal cord involvement can occur as part of systemic sarcoidosis $^{13}$.The lesion may have represented a benign tumor, such as osteoblastoma, giant cell tumor, hemangioma. It may have also represented a primary malignancy such as solitary plasmacytoma, chordoma, chondrosarcoma, lymphoma or malignant giant cell tumor ${ }^{14}$. MRI findings provided evidence against many of these diagnoses, as well as against primary intramedullary central nervous system neoplasms, such as ependymoma or astrocytoma, which are more common in children than in adults ${ }^{15}$.

Primary bone neoplasms account for fewer than $10 \%$ of all cases of bone tumors, with metastatic lesions far more widespread in the adult population. ${ }^{14}$ Bone metastases, including those to the spine, are a frequent complication of cancer (approximately $5 \%$ ), occurring most commonly in prostate cancer (up to $70 \%$ of patients) and $15 \%$ to $30 \%$ of patients with cancer of the lung, colon, stomach, bladder, rectum, thyroid and kidney ${ }^{16}$. Both osteolytic and osteoblastic metastases can cause pathologic fractures and subsequent spinal cord compression ${ }^{16}$.

With clinical features of cauda equina syndrome, anemia, high ESR, raised alkaline phosphatase, multiple myeloma with plasmacytoma formation was the most likely possibility. Magnetic resonance imaging (MRI) of his lumbar spine showed collapse with altered signal intensity in L5 \& focal altered signal intensity L1-L4, S1 vertebrae led us to do CT guided FNAC from the lesion. We went for myeloma screen by skeletal survey, urinary Bence Jones protein, plasma protein electrophoresis, immune electrophoresis \& bone marrow study. To rule out metastatic lesions, we went for common tumor markers as our patient's age, weight loss, metastatic prostate cancer was considered as one of our differential diagnosis. FNAC from vertebral lesion, bone marrow findings together with protein electrophoresis and radiographic images, confirmed the diagnosis of cauda equina syndrome due to multiple myeloma. 
Making the diagnosis includes demonstrating these M-proteins in either serum or urine, proving the presence of more than $10 \%$ of these malignant plasma cells in the bone marrow and observing the clinical manifestations of the disease in our patient ${ }^{17,18,20}$. Spinal cord compression following vertebral compression fractures or vertebral plasmacytomas comprises $5 \%$ of the presentations of multiple myeloma ${ }^{17,} 18,21$.

Our review of recent articles revealed few case reports of plasmacytomas as initial presentations of multiple myeloma. ${ }^{19,21,22}$ Despite identifying such a mass as plasmacytoma, additional tests are required to distinguish between a solitary plasmacytoma of the bone, an extramedullary plasmacytoma or the systemic disease multiple myeloma. Patients with solitary plasmacytoma of the bone are more likely to progress to multiple myeloma than those ith extramedullary plasmacytoma, but both conditions have a better overall prognosis than the systemic disease ${ }^{19,} 12,23$.

We treated the patient with radiotherapy, dexamethasone, antimyeloma therapy \& rehabilitation in collaboration with hematologist \& neurosurgeon. He showed significant improvement both clinically \& biochemically in the follow up.

\section{Conclusion:}

Diagnosis of cauda equine syndrome must be rapid in order to avoid complication. The site and morphology of the lesion should be identified as precisely as possible. Compression of spinal cord or cauda equina is relatively uncommon presentation of multiple myeloma. Meticulous history taking, examination, biochemical parameters guide the right way further investigations. Prompt diagnosis, treatment, regular follow up in essential as these are the most important part deciding prognosis.

\section{References:}

1. Kyle RA, Gertz M.A, Witzig T. E et al., "Review of 1027 patients with newly diagnosed multiple myeloma," Mayo Clinic Proceedings, vol. 78, no. 1, pp. 21-33, 2003.

2. Croucher P I and J Apperley JF, "Bone disease in multiple myeloma," British Journal of Haematology. 1998; 103( 4)902-10
3. Lecouvet FE, Vande Berg BC,Maldague BE et al., "Vertebral compression fractures inmultiple myeloma. Part I. Distribution and appearance at MR imaging," Radiology 1997 ; 204(1) 195-99

4. Prasad $D$ and Schiff $D$, "Malignant spinal-cord compression," The Lancet Oncology 2005;6( 1) $15-24$

5. Bach F, B. H. Larsen BH, RohdeK et al, "Metastatic spinal cord compression," Acta Neurochirurgica, 1990;107(1-2)37-43

6. S. Helweg-Larsen and P. S. Sorensen, "Symptoms and signs in metastatic spinal cord compression: a study of progression from first symptom until diagnosis in 153 patients," European Journal of Cancer A 1994;30( 3): 396-98

7. Levack P, Graham J, Collie Det al. “Don't wait for a sensory level-Listen to the symptoms: a prospective audit of the delays in diagnosis ofmalignant cord compression," Clinical Oncology 2002; 14(6): 472-80

8. Lecouvetn FE, Vande Berg BC, Maldague B $\mathrm{E}$ et al. "Vertebral compression fractures inmultiplemyeloma. Part I. Distribution and appearance at MR imaging," Radiology 1997;204, pp. 195-99

9. A. Baur A, St"abler A, Br"uning $R$ et al., "Diffusion-weighted MR imaging of bonemarrow: differentiation of benign versus pathologic compression fractures," Radiology 1998;207(2) 349-56

10. Flouzat-Lachaniette $\mathrm{CH}$, Allain J, RoudotThoraval F, and Poignard A, "Treatment of spinal epidural compression due to hematological malignancies: a single institution's retrospective experience," European Spine Journal 2013;22: 548-55

11. Al-Deeb SM, Yaqub BA, Sharif HS, Motaery KR: Neurotuberculosis: a review. Clin Neurol Neurosurg 1992; 94(Suppl):S30-S33.

12. Bahemuka M, Murungi JH: Tuberculosis of the nervous system: a clinical, radiological and pathological study of 39 consecutive cases in Riyadh, Saudi Arabia. J Neurol Sci 1989; 90(1):67-76. 
13, Saleh S, Saw C, Marzouk K, Sharma $\mathrm{O}$ : Sarcoidosis of the spinal cord: literature review and report of eight cases. J Natl Med Assoc 2006, 98(6):965-76.

14. Weinstein JN, McLain RF: Primary tumors of the spine. Spine 1987, 12(9):843-51.

15. Shrivastava RK, Epstein FJ, Perin NI, Post $K D$, Jallo GI: Intramedullary spinal cord tumors in patients older than 50 years of age: management and outcome analysis. J Neurosurg Spine 2005; 2(3):249-55.

16. Saleh S, Saw C, Marzouk K, Sharma $\mathrm{O}$ : Sarcoidosis of the spinal cord: literature review and report of eight cases. J Natl Med Assoc 2006; 98(6):965-76.

17. Roodman GD: Mechanisms of bone metastasis. N Engl J Med 2004; 350(16): 1655-64.

18. George ED, Sadovsky R: Multiple myeloma: recognition and management. Am Fam Physician 1999; 59(7):1885-94.
19. Kyle RA, Gertz MA, Witzig TE, Lust JA, Lacy $M Q$, Dispenzieri A et al. Review of 1027 patients with newly diagnosed multiple myeloma. Mayo Clin Proc 2003; 78(1):21-33.

20. Nofsinger YC, Mirza N, Rowan PT, Lanza D, Weinstein G: Head and neck manifestations of plasma cell neoplasms. Laryngoscope 1997; 107(6):741-746.

21. Wavre A, Baur AS, Betz M, Muhlematter D, Jotterand $\mathrm{M}$, Zaman $\mathrm{K}$ et al.: Case study of intracerebral plasmacytoma as an initial presentation of multiple myeloma. Neuro Oncol 2007; 9(3):370-72.

22. Ustuner Z, Basaran M, Kiris T, Bilgic B, Sencer $S$, Sakar B et al. Skull base plasmacytoma in a patient with light chain myeloma. Skull Base 2003; 13(3):167-71.

23. Corwin J, Lindberg RD: Solitary plasmacytoma of bone versus extramedullary plasmacytoma and their relationship to multiple myeloma. Cancer 1979; 43(3):1007-13. 